\title{
Beneficial effects of 2,4-diacetylphloroglucinol- producing pseudomonads on the marine alga Saccharina latissima
}

\author{
Kerstin Nagel, Imke Schneemann, Inga Kajahn, Antje Labes, Jutta Wiese, \\ Johannes F. Imhoff*
}

Kieler Wirkstoff-Zentrum (KiWiZ) am Helmholtz-Zentrum für Ozeanforschung (GEOMAR), Am Kiel-Kanal 44, 24106 Kiel, Germany

\begin{abstract}
Pseudomonas strains were shown to be regularly associated with the brown macroalga Saccharina latissima from the Baltic Sea, studied over several years, and were identified as producers of the antimicrobially active compound 2,4-diacetylphloroglucinol. These findings support the assumption of a stable association between the Pseudomonas spp. strains and $S$. latissima in the Baltic Sea. The metabolite profile of the Pseudomonas spp. comprised monoacetylphloroglucinol, 2,4-diacetylphloroglucinol, pyoluteorin and several rhizoxins, which exhibited broad-spectrum antibiotic activities against Gram-positive and Gram-negative bacteria as well as against fungi. Because the antibiotic activities included the inhibition of the 2 algal pathogens Pseudoalteromonas elyakovii and Algicola bacteriolytica, we propose a beneficial effect of these marine pseudomonads on their host $S$. latissima.
\end{abstract}

KEY WORDS: Pseudomonas protegens · Alga-bacteria association · 2,4-diacetylphloroglucinol · Pyoluteorin $\cdot$ Rhizoxin $\cdot$ Brown macroalgae

\section{INTRODUCTION}

Marine macroalgae continuously come into contact with microorganisms (Potin 2002), which eventually colonise the algal surfaces. As a result of numerous biological interactions, complex and changeable communities have evolved on macroalgal surfaces (Goecke et al. 2010). Given this and the fact that algae lack cell-based immune responses, it is reasonable to postulate the production of bioactive secondary metabolites as a fundamental defence mechanism against microbial attack (Engel et al. 2002, Thomas et al. 2008). It is well known that many substances within microbe-host interactions are produced by the microorganisms (Jensen \& Fenical 1994, Schmidt 2005, König et al. 2006, Egan et al. 2008, Lane \& Kubanek 2008). Pseudomonas species are well known producers of bioactive compounds
(Bérdy 2005) with diverse chemical structures (Isnansetyo \& Kamei 2009), as reflected by the ca. 900 compounds described in the Dictionary of Natural Products (Buckingham 2011).

Though marine Pseudomonas isolates have been obtained from various marine macroorganisms, such as tunicates, sponges, and turtle grass but also red algae (Isnansetyo et al. 2001, Isnansetyo \& Kamei 2009), their secondary metabolites are not well studied (Isnansetyo \& Kamei 2009). As an example, the lethal activity of marine Pseudomonas stutzeri against the red tide toxic phytoplankton Chattonella antiqua has been reported (Hayashida et al. 1991). Neither deleterious effects nor beneficial interactions with macroalgae have been reported for Pseudomonas species prior to the present study.

The bacterial communities of the brown macroalga Saccharina latissima (synonym Laminaria sac- 
charina) harbour a large number of antimicrobially active bacteria, including several Pseudomonas species (Wiese et al. 2009). Secondary metabolites are proposed to positively affect the survival of their producers (for review, see Goecke et al. 2010). Also, the host may benefit from inhibition of competing, degrading and potentially pathogenic surfacecolonising microorganisms. The complex situation of microbe-macroorganism interaction is poorly understood, especially in situ. However, more and more evidence has recently been provided by studies on the effect of microbes on their hosts (see Goecke et al. 2010). The present study contributes to the understanding of these interactions using the system of the marine alga $S$. latissima and its associated bacteria: we have identified several secondary metabolites produced by pseudomonads isolated from $S$. latissima. Their production is considered to be in favour of both the producing bacteria and their host, as described for other systems (see Goecke et al. 2010). Algae are afflicted by diseases, like many other living organisms. However, basic information concerning their pathogens is lacking (Gachon et al. 2010). Because 2,4-diacetyl-phloroglucinol (DAPG), monoacetylphloroglucinol (MAPG) and pyoluteorin (PLT) are active against Pseudoalteromonas elyakovii and Algicola bacteriolytica, which are hypothesized to cause disease of Saccharina japonica (Sawabe et al. 1998, 2000), we suppose that through production of these antibiotic compounds, the marine pseudomonads may be beneficial for the macroalgal host.

\section{MATERIALS AND METHODS}

\section{Collection of algae}

Live specimen of Saccharina latissima (phyllosphere) were collected in October 2002, May 2003 and January 2010 in the Kiel Fjord, Baltic Sea (Germany) at $6 \mathrm{~m}$ depth by SCUBA divers. Additionally, in 2010, 5 specimens each of the rhizosphere and S. latissima were taken from the same habitat.

\section{Isolation and identification of antimicrobially active Pseudomonas spp.}

In 2002 and 2003, bacteria were isolated from Saccharina latissima according to Wiese et al. (2009). From a greater number of isolates, 13 Pseudomonas strains demonstrated antibiotic activity and were selected for investigation of secondary metabolite production. Three further isolates were chosen from the collection of Pseudomonas spp. strains obtained in 2010 by the following procedure: The algae were homogenised, and the suspensions of different dilution series as well as the rhizosphere suspension were plated on 3 different media: (1) Medium G, GSP agar according to Kielwein (1971), (2) Medium P prepared according to Kalinovskaya et al. (2004) and modified by supplementation with $18 \mathrm{~g}$ Tropic Marin sea salt (Dr. Biener) and $15 \mathrm{~g}$ Bacto agar in $1 \mathrm{l}$ deionised water, $\mathrm{pH}$ 7.6, and (3) Medium $\mathrm{C}$, a Pseudomonas selective agar base supplemented with Pseudomonas CFC selective supplement (Merck), $\mathrm{pH}$ 7.2. Incubation was carried out in the dark at $28^{\circ} \mathrm{C}$ for $5 \mathrm{~d}$. The light regime of the sampling site was not considered as a parameter for setting the culture conditions. Pure cultures were obtained by subsequent plating steps on Bacto marine broth agar (MB) with $37.4 \mathrm{~g} \mathrm{l}^{-1}$ marine broth and $15 \mathrm{~g} \mathrm{l}^{-1}$ agar. The pure cultures were stored at $-80^{\circ} \mathrm{C}$ using the Cryobank System (Mast Diagnostica), according to the manufacturer's instructions. 'Pseudomonas-like colonies' (as determined by growth on selective media, colony form and microscopic analysis) were identified by 16S rRNA gene sequence analysis according to Thiel et al. (2007) using the Basic Local Alignment Search Tool with the European Molecular Biology Laboratory (EMBL) nucleotide database (Altschul et al. 1990) and the Ribosomal Database Project II (RDP-II) website (Cole et al. 2007).

\section{Strain identification and phylogenetic analysis}

The Ribosomal Database Project database was used to select the next related type strains (http:// rdp.cme.msu.edu; Cole et al. 2009). Sequence similarity values were determined with the 'bl2seq' tool of the National Center for Biotechnology Information database (http://blast.ncbi.nlm.nih.gov/; Tatusova \& Madden 1999). The alignment of the $16 \mathrm{~S}$ rRNA gene sequences of the strains LD45, LD46, LD47, LD49, LD51，LD52，LD53，LM59，LB062a，LD115，LD118, LD119, LD120, LB183, LB184 and LB185, including type strains of Pseudomonas fluorescens and Azotobacter vinelandii, was performed with Clustal X (Larkin et al. 2007) and refined manually. A. vinelandii was selected as an outgroup. All sequences were cut to the same length of 1401 base pairs. LD120, LB183 and LB184 were selected as representatives of the alga-associated isolates for the phylogenetic analysis. The phylogenetic trees were calcu- 
lated by the neighbour-joining method (Saitou \& Nei 1987) and maximum-likelihood method (Felsenstein 1981) using MEGA version 3.1 (Kumar et al. 2004) and PhyML Online (Guindon et al. 2005), respectively. A total of 1000 bootstrap replicates were applied for the neighbour-joining analysis and 500 bootstrap replicates for the maximum-likelihood analysis. The maximum-likelihood tree was calculated using the GTR model and an estimated proportion of invariable sites as well as the Gamma distribution parameter. NJplot was used to display the phylogenetic trees (http://pbil.univ-lyon1.fr/ software/njplot.html; Perrière \& Gouy 1996).

Additionally, to confirm the phylogenetic identification by $16 \mathrm{~S}$ rRNA gene sequence analysis, strain LD120 was examined for its physiological characteristics and pigment production. For the physiological characterisation, the utilisation of 95 carbon sources by strain LD120 was examined with the GN2 MicroPlate system (BIOLOG) following the manufacturer's instructions in duplicates. Biolog GN2 plates contain 96 wells. Each well, except for a negative control (water), contains a unique carbon source and the metabolic indicator tetrazolium violet. A colour change of tetrazolium violet allows identification of metabolism based on the exchange of electrons generated during respiration. The results of strain LD120 were compared to the phenotypic characterisation chart according to Rico \& Preston (2008).

Pigment production is a characteristic of fluorescent pseudomonads (Stanier et al. 1966). Strain LD120 was grown on Medium P for $3 \mathrm{~d}$ at $28^{\circ} \mathrm{C}$ in the dark and examined for the production of fluorescein using a UV lamp (366 nm).

\section{Substrate utilisation of Pseudomonas sp. strain LD120}

To prove whether strain LD120 is able to digest algal compounds, it was grown on minimal medium containing $1.5 \%(\mathrm{w} / \mathrm{v})$ Bacto agar for solidification and the following substrates $(1 \%$ (w/v)): sodium alginate, cellulose, mannitol, glucose, freeze dried Saccharina latissima (powder), agarose, DL sodium malate, sodium succinate, sodium fumarate and L sodium glutamate. All substrates were dissolved in sterile sea water with salinity according to the sampling site. Inoculation was accomplished by streaking a 5 d old culture from an MB agar plate. Growth was monitored for $12 \mathrm{~d}$ in the dark at $28^{\circ} \mathrm{C}$. As a control for growth, cultures were grown on $\mathrm{MB}$ agar.

\section{Selection of DAPG-producing Pseudomonas strains}

According to their production of DAPG, 16 Pseudomonas strains were selected, all of which showed a colour change of MB agar plates indicating DAPG production as reported by Bangera \& Thomashow (1996) and Keel et al. (1996). DAPG production in culture extracts was verified by high-performance liquid chromatography (HPLC) with diode-array detection and mass spectrometry (HPLC-DAD-MS) analysis (Bonsall et al. 1997).

\section{Cultivation and extraction of agar plates}

Cultures of all strains were grown for $7 \mathrm{~d}$ at $28^{\circ} \mathrm{C}$ in the dark on $\mathrm{MB}$ agar medium until a dense bacterial lawn was obtained on the plates. The cultures, including the agar, were homogenised and extracted using $20 \mathrm{ml}$ ethyl acetate. The organic phase was separated, dried in vacuo and subsequently dissolved in $200 \mu \mathrm{l}$ methanol. These extracts were used for chemical analyses.

\section{Cultivation of Pseudomonas strain LD120}

Pseudomonas strain LD120 was chosen for isolation of substances and was grown in 21 Erlenmeyer flasks each containing $1 \mathrm{l}$ of TM medium $\left(5.0 \mathrm{~g} \mathrm{l}^{-1}\right.$ papaic digest of soybean meal, $1.0 \mathrm{~g} \mathrm{l}^{-1}$ Bacto yeast extract, $30.0 \mathrm{~g} \mathrm{l}^{-1}$ Tropic Marin sea salt and $1 \mathrm{l}$ deionised water at $\mathrm{pH} 7.7$ ) for $48 \mathrm{~h}$ at $28^{\circ} \mathrm{C}$ under shaking conditions (120 rpm). Each culture was inoculated separately with a $2 \mathrm{~cm}^{2}$ piece from a preculture grown on agar plates ( $20 \mathrm{~d}$ old, $25^{\circ} \mathrm{C}$, dark). A total of 101 of culture broth was extracted with the same volume of ethyl acetate. The extract was the source of compounds for chemical analyses and antimicrobial testing.

\section{Analytical HPLC analyses}

Chemical analyses and dereplication of substances was done according to Schneemann et al. (2010b) by comparison of MS and UV data obtained by HPLCUV-MS analyses. Reversed phase HPLC experiments were performed using a C18 column (Phenomenex Onyx Monolithic C18, $100 \times 3.00 \mathrm{~mm}$ ) applying an $\mathrm{H}_{2} \mathrm{O}(\mathrm{A})$ /acetonitrile $\left(\mathrm{C}_{2} \mathrm{H}_{3} \mathrm{~N}\right)(\mathrm{B})$ gradient with $0.1 \%$ $\mathrm{HCOOH}$ added to both solvents (gradient 0 min $5 \%$ B, 4 min $60 \%$ B, 6 min $100 \%$ B; flow $2 \mathrm{ml} \mathrm{min}^{-1}$ ) on a 
VWR Hitachi Elite LaChrom system coupled to an ESI-ion trap detector (Esquire 4000, Bruker Daltonics). The retention times of MAPG, DAPG and PLT were 1.9 to $2.1 \mathrm{~min}, 3.5$ to $3.7 \mathrm{~min}$ and 3.0 to $3.1 \mathrm{~min}$, respectively. Rhizoxins eluted between 3.5 and $4.9 \mathrm{~min}$.

\section{Preparative HPLC analyses}

The extract was subjected to preparative HPLC (eluents: $\mathrm{H}_{2} \mathrm{O}[\mathrm{A}]$, acetonitrile [B]; gradient $0 \mathrm{~min}$ $20 \%$ B, 18 min 100\% B; flow $15 \mathrm{ml} \mathrm{min}^{-1}$ ). MAPG, DAPG and PLT eluted at 5.7 to $5.9 \mathrm{~min}, 7.0$ to $7.2 \mathrm{~min}$ and 8.6 to $8.8 \mathrm{~min}$, respectively. Preparative HPLC was carried out using a Merck Hitachi system consisting of an L-7150 pump, an L-2200 autosampler and an L-2450 diode array detector with a Phenomenex Gemini-NX C18 column (5 $\mu \mathrm{m}, 110 \AA$, Axia packed; $100 \times 21.20 \mathrm{~mm})$.

\section{Antimicrobial assays}

Antimicrobial assays were performed using 18 test strains (see Table 3). Among them were Algicola bacteriolytica, which is hypothesized to be the causative agent of red-spot disease in the brown alga Saccharina japonica (Sawabe et al. 1998), and Pseudoalteromonas elyakovii, an alginolytic marine bacterium isolated from a spot-diseased S. japonica (Sawabe et al. 2000). Both Trichophyton species (see Table 3) were from the Department of Dermatology, Allergology and Venerology, University Hospital SchleswigHolstein, Kiel, Germany.

For cultivation of the test strains, the following media were used: (1) TSB3+ medium (3 $\mathrm{g} \mathrm{l}^{-1}$ tryptic soy broth, $\left.5 \mathrm{~g} \mathrm{l}^{-1} \mathrm{NaCl}\right)$, (2) TSB12+ medium (12 $\mathrm{g} \mathrm{l}^{-1}$ tryptic soy broth, $5 \mathrm{~g} \mathrm{l}^{-1} \mathrm{NaCl}$ ), (3) M1 medium (5 $\mathrm{g} \mathrm{l}^{-1}$ Bacto-peptone, $3 \mathrm{~g} \mathrm{l}^{-1}$ meat extract, $\mathrm{pH}$ 7.0), (4) modified M186 medium (1 $\mathrm{g} \mathrm{l}^{-1}$ yeast extract, $1 \mathrm{~g} \mathrm{l}^{-1}$ malt extract, $1.67 \mathrm{~g} \mathrm{l}^{-1}$ peptone from soybeans, $3.3 \mathrm{~g} \mathrm{l}^{-1}$ glucose), (5) PGY medium (5 g trypticase peptone, $5 \mathrm{~g}$ Bacto-peptone, $10 \mathrm{~g}$ yeast extract, $5 \mathrm{~g}$ beef extract [BD], $5 \mathrm{~g}$ glucose, $2 \mathrm{~g}$ $\mathrm{KH}_{2} \mathrm{PO}_{4}, 1 \mathrm{ml}$ Tween 80, $40 \mathrm{ml}$ salt solution, $10 \mathrm{ml}$ haemin solution, $0.2 \mathrm{ml}$ vitamin $\mathrm{K}_{1}$ solution, $0.5 \mathrm{~g}$ cysteine- $\mathrm{HCl} \times \mathrm{H}_{2} \mathrm{O}, 950 \mathrm{ml}$ deionised water, $\mathrm{pH}$ 7.2; salt solution: $0.25 \mathrm{~g} \mathrm{CaCl}_{2} \times 2 \mathrm{H}_{2} \mathrm{O}, 0.5 \mathrm{~g} \mathrm{MgSO}_{4}$ $\times 7 \mathrm{H}_{2} \mathrm{O}, 1 \mathrm{~g} \mathrm{~K} \mathrm{HPO}_{4}, 1 \mathrm{~g} \mathrm{KH} \mathrm{KO}_{4}, 10 \mathrm{~g} \mathrm{NaHCO}$, $2 \mathrm{~g} \mathrm{NaCl}, 1000 \mathrm{ml}$ deionised water; haemin solution: $50 \mathrm{mg}$ haemin, $1 \mathrm{ml} 1 \mathrm{~N} \mathrm{NaOH}$, add distilled water to $100 \mathrm{ml}$; vitamin $\mathrm{K}_{1}$ solution: $0.1 \mathrm{ml}$ vitamin $\mathrm{K}_{1}, 20$ $\mathrm{ml} 95 \%$ ethanol), (6) MA medium (20 g malt extract, $1000 \mathrm{ml}$ deionised water), (7) PM medium (150 $\mathrm{g} \mathrm{l}^{-1}$ pea, $5 \mathrm{~g} \mathrm{l}^{-1}$ glucose, pH 6.5), (8) MYA medium (10 g malt extract, $4 \mathrm{~g}$ yeast extract, $4 \mathrm{~g}$ glucose, $\mathrm{pH}$ 5.6) and (9) SA medium (10 $\mathrm{g} \mathrm{l}^{-1}$ Bacto-peptone, $20 \mathrm{~g} \mathrm{l}^{-1}$ glucose, $\mathrm{pH}$ 5.6).

To obtain spores of the fungal strains for the subsequent testing, the method according to F. Horter (pers. comm.) was used: Agar plates with $2 \mathrm{wk}$ old cultures were covered with $10 \mathrm{ml}$ of sterile $10 \mathrm{mM}$ $\mathrm{Na}_{2} \mathrm{HPO}_{4}$ ( $\mathrm{pH}$ 7.3). Using a Drigalski-spatula, the spores were scraped off of the plates. The spore suspension was poured through a gauze bandage and washed 2 times with $10 \mathrm{mM} \mathrm{Na}_{2} \mathrm{HPO}_{4}$ (pH 7.3).

Pseudomonas sp. LD120 metabolites were adjusted to $10 \mathrm{mM}$. For all tests, a 1:5 dilution (except for $P$. infestans with a 1:10 dilution) in phosphate-buffered saline $\left(8 \mathrm{~g} \mathrm{l}^{-1} \mathrm{NaCl}, 0.2 \mathrm{~g} \mathrm{l}^{-1} \mathrm{KCL}, 1.44 \mathrm{~g} \mathrm{l}^{-1} \mathrm{Na}_{2} \mathrm{HPO}_{4}\right.$ and $0.24 \mathrm{~g} \mathrm{l}^{-1} \mathrm{KH}_{2} \mathrm{PO}_{4}, \mathrm{pH}$ 7.4) was used.

For activity tests, 96 well microtiter plates were used. Aliquots of $10.5 \mu \mathrm{l}$ of the metabolite dilution and $200 \mu \mathrm{l}$ of an overnight culture of the test strain or spore suspension were used in triplicate. Noninoculated medium, chloramphenicol $(100 \mu \mathrm{M})$ or cycloheximide $(100 \mu \mathrm{M})$, was used as the positive control; the test strains alone were used as negative controls. Bacterial growth and cell viability were estimated by measuring the optical density at $600 \mathrm{~nm}$ and using the resazurin/resorufin method as modified by Schneemann et al. (2010b). Specific conditions for the different test strains concerning the optical density of the inoculum, medium used, microtiter plate incubation temperature, aeration, light conditions, incubation time and incubation conditions are listed in Appendix 1. The assay against Propionibacterium acnes was performed according to Schneemann et al. (2010a). The inhibition of fungal strain growth was determined by measuring the optical density at $600 \mathrm{~nm}$ after 48 or $72 \mathrm{~h}$.

\section{RESULTS}

\section{Phylogenetic identification of Pseudomonas strains from Saccharina latissima}

Among a larger number of bacteria isolated from the phyllosphere and rhizosphere of Saccharina latissima specimens from the Baltic Sea, 16 strains were affiliated to the genus Pseudomonas according to $16 \mathrm{~S}$ rRNA gene sequences. These isolates originated from different sampling campaigns. Nine Pseudo- 
monas strains were isolated from the phyllosphere of the alga sampled in November 2002: strains LD45 (AM913891), LD46 (AM913892), LD47 (AM913893), LD49 (AM913894), LD51 (AM913895), LD52 (AM913896) and LD53 (AM913897), LM 59 (AM913898) and LM63 (AM913900). Four strains were obtained from phyllosphere samples in May 2003: LB062a (FR686532), LD155 (AM913903), LD118 (AM913943) and LD120 (AM913905). Three further strains were isolated in January 2010: strain LB183 (FR675975) from the phyllosphere and strains LB184 (FR675976) and LB185 (FR675977) from the rhizosphere. The accession numbers of the $16 \mathrm{~S}$ rRNA gene sequences in the EMBL database are given in parentheses.

A neighbour-joining tree was calculated to show the phylogenetic relationship of the strains (Fig. 1). The phylogenetic analysis using the maximum-likelihood method revealed the same results (data not shown). Two groups of strains were found. Most of the Pseudomonas strains associated with Saccharina latissima affiliated to $P$. protegens $\mathrm{CHAO}^{\mathrm{T}}$ with a sequence similarity of $>99.5 \%$ (Fig. 1), which also includes some strains previously misclassified as $P$. fluorescens (such as strain Pf-5) (Ramette et al. 2011). We refer to these strains as the 'LD120-group' because their 16S rRNA gene sequences showed a similarity of $100 \%$ to each other. The second group with strains LB183 and LB184 affiliated to P. brassicacearum DBK $11^{\mathrm{T}}$ (AF100321) and formed a separate cluster with similarity ranges from 97.5 to $97.8 \%$ to the 'LD120 group'.

\section{Metabolical and biochemical characterisation of strain LD120}

Because differentiation of closely related Pseudomonas species cannot be accomplished clearly based on 16S rRNA gene sequences (Peix et al. 2009), further experiments were carried out. As is typical for fluorescent Pseudomonas strains, LD120 produced a fluorescent yellowish-green-coloured pigment that diffused into the agar and showed fluorescence under the UV light. According to the Biolog system, the substrate utilisation pattern of

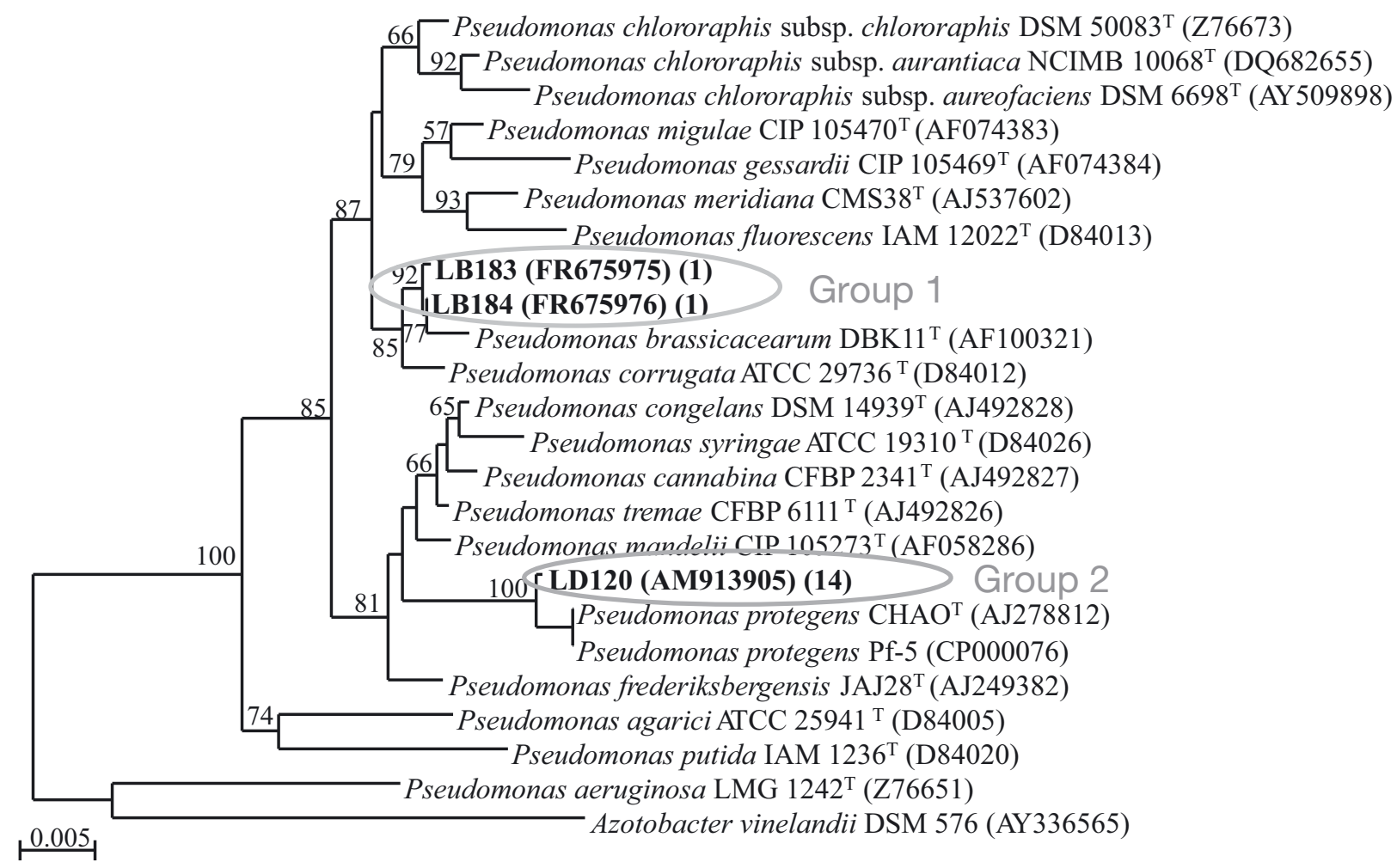

Fig. 1. Phylogenetic analysis of Pseudomonas strains associated with Saccharina latissima using the neighbour-joining method. Bootstrap values are given as percentages (only numbers above $50 \%$ are shown). The scale bar indicates the number of substitutions per nucleotide position. The strains isolated in the present study are highlighted in bold, and the number of isolated strains is shown in parentheses. Group 2, i.e. the 'LD120 group', includes sequences from the isolates LD45, LD46, LD47, LD49, LD51, LD52, LD53, LM59, LB062a, LD115, LD118, LD119, and LB185 
Pseudomonas sp. LD120 was $89 \%$ similar to that of P. protegens Pf-5 as reported by Rico \& Preston (2008). Values of 86 and $76 \%$ similarity to the substrate utilisation patterns of $P$. putida KT2440 and $P$. syringae pathovar tomato DC3000, respectively, were detected. Furthermore, strain LD120 produced the metabolites MAPG, DAPG, PLT, which are known products from $P$. protegens (Keel et al. 1996, Ramette et al. 2011). On the basis of its chemical and biochemical properties, strain LD120 was classified as a strain of $P$. protegens. According to the phylogenetic and chemical analyses, the strains from the LD120 group were classified as strains of $P$. protegens as well.

Growth of Pseudomonas sp. LD120 was not detected on sodium alginate, cellulose, freeze-dried $S$. latissima powder, agarose or agar, indicating that strain LD120 was not able to digest polymeric sugars originating from the alga. On Biolog GN2 microplates, the strain LD120 utilizes a wide spectrum of carbon sources, including a number of sugars (e.g. D-fructose, $\alpha$-D-glucose, D-mannose, sucrose, Dgluconic acid) and amino acids (e.g. L-asparagine, L-aspartic acid, L-glutamic acid, L-proline, $\gamma$-aminobutyric acid, D-alanine, L-alanine, L-leucine, Lornithine, L-threonine, L-alanyl-glycine and glycyl-Lglutamic acid). Growth occurred on minimal media with sodium salts of DL-malate, succinate, fumarate, citric acid and $\alpha$-ketoglutaric acid as substrates, with the strain showing a clear preference for dicarboxylic acids (citric acid cycle compounds) and complex media (marine broth) containing proteins.

\section{Secondary metabolites produced by Pseudomonas strains}

Concerning the strains' secondary metabolite production, 4 different production patterns of MAPG, DAPG, PLT and the rhizoxins were obtained within the Pseudomonas strains, as shown in Table 1. While the majority of the strains produced at least 2 of these metabolites in several combinations, some produced only 1 of the compounds. Strain LD120 showed the broadest metabolite pattern with the production of all 4 compounds. Therefore, strain LD120 was chosen for further analyses.

\section{Chemical analysis of culture extracts}

The secondary metabolite pattern of extracts of strain LD120 showed 15 substances (Table 2), 12 of which were identified, with MAPG, DAPG and PLT as major compounds and mainly various rhizoxin derivatives as minor compounds.

\section{Antimicrobial activities of the major secondary metabolites}

A comprehensive panel of test strains was used to study the biological activities of the isolated compounds. The selection included bacteria from a variety of groups that are present on macroalgae in the Baltic Sea (Staufenberger et al. 2008, Wiese et al. 2009), algal and plant pathogens and medically relevant strains. This broad panel should give information to indicate a possible ecological function of the compounds and identify the potential for eventual biotechnological applications.

The metabolites isolated from strain LD120 exhibited various antimicrobial activities against different test organisms (Table 3). All metabolites (Table 1) were active against the 2 tested Grampositive bacteria, but only PLT was also active against several Gram-negative bacteria. In addition to antibacterial activities, MAPG and DAPG exhibited activities against fungi, especially against the plant pathogens Septoria tritici and Phytophthora infestans as well as against the 2 dermatophytes Trichophyton mentagrophytes and $T$. rubrum. In addition, DAPG was weakly active against the yeast Candida glabrata and the phytopathogenic fungus Botrytis cinerea. PLT was active against the plant pathogens Pseudomonas syringae, Erwinia amylovora, Ralstonia solanacearum and Xanthomonas campestris as well as the algal pathogens Algicola bacteriolytica and Pseudoalteromonas elyakovii, whereas DAPG showed inhibition of $E$. amylovora and A. bacteriolytica.

Table 1. Patterns of secondary metabolites produced by Pseudomonas strains as revealed by HPLC-UV-MS analyses. MAPG: monoacetylphloroglucinol, DAPG: 2,4-diacetylphloroglucinol, PLT: pyoluteorin, + : production of metabolite was detected, -: production of metabolite was not detected

\begin{tabular}{|c|c|c|c|c|}
\hline Strain & MAPG & DAPG & PLT & Rhizoxins \\
\hline LD120 & + & + & + & + \\
\hline 13 strains $^{\mathrm{a}}$ & - & + & + & - \\
\hline LB184 & - & + & - & - \\
\hline LB183 & + & + & - & - \\
\hline \multicolumn{5}{|c|}{$\begin{array}{l}\text { aStrains LB062a, LB185, LD46, LD47, LD49, LD51, LD52, } \\
\text { LD53, LD115, LD118, LM59, LM63, LD45 }\end{array}$} \\
\hline
\end{tabular}


Table 2. Pseudomonas protegens. Secondary metabolites identified in cultures of strain LD120. MS: mass spectrometry, UV: ultraviolet detection, ${ }^{1} \mathrm{H}-\mathrm{NMR}$ : proton nuclear magnetic resonance; $\mathrm{m} / \mathrm{z}$ : mass-tocharge ratio; $[\mathrm{M}+\mathrm{H}]^{+}$: protonated molecular mass

\begin{tabular}{|lccc|}
\hline No. & Compound & Dereplication & $\begin{array}{c}\mathrm{m} / \mathrm{z} \\
{[\mathrm{M}+\mathrm{H}]^{+}}\end{array}$ \\
\hline 1 & Monoacetylphloroglucinol & MS, UV, ${ }^{1} \mathrm{H}-\mathrm{NMR}$ & 169 \\
2 & 2,4-diacetylphloroglucinol & MS, UV, ${ }^{1} \mathrm{H}-\mathrm{M} \mathrm{R}$ & 211 \\
3 & Pyoluteorin & MS, UV, ${ }^{1} \mathrm{H}-\mathrm{NMR}$ & 272 \\
4 & Rhizoxin S1 & MS, UV & 614 \\
5 & Rhizoxin S2 & MS, UV & 628 \\
6 & Rhizoxin D1 & MS, UV & 580 \\
7 & Rhizoxin D3 & MS, UV & 598 \\
8 & Rhizoxin M1 & MS, UV & 628 \\
9 & Rhizoxin Z1 & MS, UV & 628 \\
10 & WF1360B (rhizoxin derivative) & MS, UV & 596 \\
11 & WF1360D (rhizoxin derivative) & MS, UV & 596 \\
12 & WF1360F (rhizoxin derivative) & MS, UV & 610 \\
13 & Unknown compound 1 & MS, UV & 348 \\
14 & Unknown compound 2 & MS, UV & 322 \\
15 & Unknown compound 3 & MS, UV & 320 \\
\hline
\end{tabular}

bacteria (Wiese et al. 2009). Based on the repeated isolation of pseudomonads from the Baltic Sea site, we have demonstrated an enduring association of pseudomonads with S. latissima. Specific association of bacterial communities was found on different parts of $S$. latissima originating from the Baltic Sea and North Sea (Staufenberger et al. 2008). This likely stable association with the alga raises the question of whether the pseudomonads are of particular importance for S. latissima. As epibiotic bacteria are fast colonisers, highly adaptive and rapidly metabolise algal exudates (Goecke et al. 2010), pseudomonads could have an advantage compared to other bacteria due to their production of secondary metabolites, which are active against competitive microorganisms.

The ability of marine bacteria to produce secondary metabolites has been established.

\section{DISCUSSION}

\section{Saccharina latissima and pseudomonads}

As revealed in a previous cultivation-based study, members of the genera Streptomyces and Bacillus together with pseudomonads, associated with the marine brown macroalga Saccharina latissima, represented high proportions of antimicrobially active
In addition to structural variety, bioactive compounds obtained from marine microorganisms are known for their broad range of biological effects, which include antimicrobial antiprotozoan, antiparasitic, and antitumour activities. Surface-associated microorganisms supposedly have developed specialised and stable adaptations specific to the microenvironment created by a particular host (Penesyan et al. 2010). Therefore, our research focused on antimicrobially active

Table 3. Antimicrobial activities of metabolites from Pseudomonas protegens strain LD120 tested at concentrations of $100 \mu \mathrm{M}$ (50 $\mathrm{\mu M}$ for Phytophtora infestans). Activities of $\geq 80 \%$ inhibition are highlighted in bold. MAPG: monoacetylphloroglucinol, DAPG: 2, 4-diacetylphloroglucinol, PLT: pyoluteorin

\begin{tabular}{|llrr|} 
& & & \\
& Description & Inhibition (\%) & DAPG \\
\cline { 2 - 4 } Test strain & & MAPG & $\mathbf{1 0 0}$ \\
Bacillus subtilis (DSM 347) & Gram-positive & $\mathbf{1 0 0}$ & $\mathbf{1 0 0}$ \\
Staphylococcus lentus (DSM 6672) & Gram-positive & $\mathbf{9 7}$ & $\mathbf{1 0 0}$ \\
Escherichia coli (DSM 498) & Gram-negative & 31 & 0 \\
Pseudomonas fluorescens (NCIMB 10586) & Gram-negative & 0 & 37 \\
Pseudomonas syringae (DSM 50252) & Phytopathogenic bacterium & 0 & 0 \\
Erwinia amylovora (DSM 50901) & Phytopathogenic bacterium & 0 & 75 \\
Ralstonia solanacearum (DSM 9544) & Phytopathogenic bacterium & 0 & 0 \\
Xanthomonas campestris (DSM 2405) & Phytopathogenic bacterium & 0 & $\mathbf{9 7}$ \\
Botrytis cinerea (BASF) & Phytopathogenic fungus & 26 & $\mathbf{9 3}$ \\
Phytophthora infestans (BASF) & Phytopathogenic fungus & $\mathbf{8 6}$ & $\mathbf{1 0 0}$ \\
Septoria tritici (BASF) & Phytopathogenic fungus & $\mathbf{9 0}$ & $\mathbf{9 6}$ \\
Algicola bacteriolytica (CIP 105725) & Algal pathogen & $\mathbf{1 0 0}$ \\
Pseudoalteromonas elyakovii (CIP 105338) & Algal pathogen & $\mathbf{8 0}$ \\
Pseudomonas aeruginosa (DSM 50071) & Clinical pathogen & 0 & 0 \\
Propionibacterium acnes (DSM 1897) & Clinical pathogen & 0 & $\mathbf{8 9}$ \\
Candida glabrata (DSM 6425) & Yeast & $\mathbf{9 5}$ & $\mathbf{9 4}$ \\
Trichophyton mentagrophytes & Dermatophyte & 30 & 0 \\
Trichophyton rubrum & Dermatophyte & $\mathbf{9 4}$ & $\mathbf{9 7}$ \\
& & $\mathbf{9 8}$ & 29 \\
\end{tabular}


Pseudomonas strains, which were isolated from Saccharina latissima and showed a reddish colour change on $\mathrm{MB}$ medium, indicating the production of the bioactive DAPG (Bangera \& Thomashow 1996, Keel et al. 1996). The classification of these pseudomonads revealed the affiliation to 2 separate clusters within the genus Pseudomonas (Fig. 1). Most of the strains, including strain LD120, affiliated to Pseudomonas protegens. In addition, these strains produced at least 1 of the biologically active metabolites MAPG, PLT and rhizoxins. The most potent producer was $P$. protegens strain LD120, which was characterized in regard to utilization of substrate possibly originating from the alga and was chosen for detailed chemical analyses.

\section{Metabolic properties of strain LD120}

The analysis of strain LD120 in respect of its capability to degrade selected carbon sources possibly deriving from the alga showed that growth did not occur on minimal media with powdered and freezedried Saccharina latissima or on minimal media supplemented with alginate, an important algal polysaccharide comprising 30 to $36 \%$ of algal dry weight (Obluchinskaya 2008). Mannitol, a main storage component of S. latissima that can be accumulated up to $15 \%$ of absolute algal dry weight (Obluchinskaya 2008), was not utilised as a growth substrate either. These findings indicate that macromolecular structures of living, healthy algae are not attacked by this bacterium (Kremer \& Markham 1979), and strain LD120 is proposed to be non deleterious to the healthy algal host. However, macroalgae are known to release large amounts of organic carbon, e.g. amino acids and sugars, into the surrounding environment (providing nutrients for microorganisms) (Goecke et al. 2010), which are also released during fragmentation of kelp. These compounds presumably represent substrates for the Pseudomonas strains, a hypothesis that is supported by the wide spectrum of substrates used from the BIOLOG test system, including a number of organic acids (e.g. tricarboxylic acid cycle compounds), sugars and amino acids.

\section{Bioactivity of metabolites produced by Pseudomonas strains}

The metabolites DAPG, MAPG, PLT and rhizoxins, which were produced by the Pseudomonas strains associated with the marine alga Saccharina latissima, have also been discussed as products of Pseudomonas isolates from terrestrial plants (Tatusova \& Madden 1999, Brodhagen et al. 2004, Weller et al. 2007, Loper et al. 2008). Fluorescent Pseudomonas species have been studied for decades with regard to their plant growth-promoting effects through the effective suppression of soilborne plant diseases (Nowak-Thompson et al. 1994, Weller 2007). The modes of action playing a role in disease suppression by these bacteria include siderophore-mediated competition for iron, production of lytic enzymes, induced systemic resistance and antibiosis (Bakker et al. 2007). Root-colonising, plant-beneficial pseudomonads release a remarkable diversity of metabolites with antibiotic activity, such as the polyketidic compounds DAPG and PLT (Brodhagen et al. 2004, Dubuis et al. 2007). We demonstrated that these metabolites are produced by Pseudomonas strains associated with S. latissima. DAPG, MAPG, PLT and rhizoxins are thus proposed to be chemical mediators of antibacterial, antifungal, cytotoxic and antiprotozoal effects for possible protection of the alga, as shown for terrestrial pseudomonad-host plant associations (Iwasaki et al. 1984, Kiyoto et al. 1986, de Souza et al. 2003, Isnansetyo et al. 2003, Jousset et al. 2006). Both DAPG and PLT produced by the Pseudomonas strains in the present study are able to suppress the algal pathogens Algicola bacteriolytica and Pseudoalteromonas elyakovii.

Previously, Armstrong et al. (2001) reported that epibionts in the marine environment play a protective role by releasing compounds into the surrounding seawater and thereby acting against other microorganisms, potentially both competitors and pathogens. Other reports indicated that epiphytic bacteria, which produce bioactive substances, enhanced the fitness of their algal host (Rao et al. 2007). We suggest that the metabolites DAPG, MAPG, PLT and rhizoxins act against competitors and degrading or other deleterious microorganisms, like fungal and bacterial pathogens of Saccharina latissima. The rhizoxins, highly antibiotic and antimitotic compounds are known products of the fungusassociated Burkholderia rhizoxinica as well as of Pseudomonas protegens Pf-5 (Partida-Martinez \& Hertweck 2005, Scherlach et al. 2006, Loper et al. 2008). Rhizoxin and its derivatives were reported to significantly inhibit growth of the plant pathogenic fungus Fusarium oxysporum. However, rhizoxin S2 is also the causal agent of rice seedling blight, and therefore, the ecological role of the rhizoxins may well be considered to be context-dependent (Brendel et al. 2007). 
In our bioassay panel, DAPG, MAPG and PLT demonstrated a broad range of bioactivities. Noticeably, they showed strong biological activities against phytopathogenic bacteria and fungi and also against specific algal pathogens. In particular, PLT showed good activity against the 2 algal pathogens Algicola bacteriolytica and Pseudoalteromonas elyakovii. A. bacteriolytica is a marine bacterium that might be the causative agent of red spot disease of Saccharina japonica (synonym Laminaria japonica), leading to a decrease in the seed supply of the alga (Sawabe et al. 1998). P. elyakovii is an alginolytic marine bacterium and was isolated from spot-wounded fronds of $S$. japonica. Both bacteria may induce severe damage to Saccharina crops (Sawabe et al. 2000) owing to complete thallus degradation of kombu within 1 wk (Sawabe et al. 1992). Thus, concerted action of these 3 compounds (DAPG, MAPG and PLT) could promote protective properties against these pathogenic microorganisms. Inhibitory activities against other epiphytic bacteria are of great importance in microhabitats on the algal surface, where competition for an attachment site is frequent. The competition for space between epibiotic bacteria based on bioactive compounds may provide an antifouling protection to the algal basibiont.

\section{CONCLUSION}

We demonstrated that members of Pseudomonas species regularly occur on the surface of Saccharina latissima in the Baltic Sea. The secondary metabolites acetylphloroglucinols (MAPG and DAPG) and PLT produced by these bacteria exhibited antimicrobial activities against algal pathogens and a broad range of bacteria and fungi. Based on these findings, we propose a beneficial effect of these Pseudomonas strains on $S$. latissima and their possible activity in preventing fouling processes. Further studies are needed to clarify the localisation and seasonal occurrence of Pseudomonas cells on $S$. latissima and also identify the antimicrobial compounds in situ to demonstrate their ecological role.

Acknowledgements. The authors gratefully thank K. Schumann for cultivation experiments, A. Erhard for bioactivity assays, G. Kohlmeyer-Yilmaz as well as F. Sönnichsen of the Otto Diels Institute of Organic Chemistry (University Kiel, Germany) for running and processing nuclear magnetic resonance experiments, and T. Staufenberger and H. Heindl for taking samples by SCUBA diving. The authors are grateful to Dr. J. B. Speakman (BASF) for providing Botrytis cinerea, Phytophthora infestans and Septoria tritici as well as for sup- port in their cultivation. Many thanks also to F. Horter (AG Prof. Dr. J. Brasch, Department of Dermatology, University Medical Center Schleswig-Holstein, Kiel, Germany) for providing Trichophyton mentagrophytes and T. rubrum as well as for the instruction regarding the cultivation of these strains. The present study is from the Kieler Wirkstoff-Zentrum KiWiZ (Center for Marine Natural Products), which was supported by the Ministry of Science, Economic Affairs and Transport of the State of Schleswig-Holstein (Germany) within the framework of the 'Future Program for Economy', co-financed by the European Union (EFRE).

\section{LITERATURE CITED}

Altschul SF, Gish W, Miller W, Myers EW, Lipman DJ (1990) Basic local alignment search tool. J Mol Biol 215:403-410 Armstrong E, Yan L, Boyd KG, Wright PC, Burgess JG (2001) The symbiotic role of marine microbes on living surfaces. Hydrobiologia 461:37-40

Bakker PAHM, Pieterse CMJ, van Loon LC (2007) Induced systemic resistance by fluorescent Pseudomonas spp. Phytopathology 97:239-243

Bangera MG, Thomashow LS (1996) Characterization of a genomic locus required for synthesis of the antibiotic 2,4-diacetylphloroglucinol by the biological control agent Pseudomonas fluorescens Q2-87. Mol Plant Microbe Interact 9:83-90

Bérdy J (2005) Bioactive microbial metabolites. J Antibiot (Tokyo) 58:1-26

Bonsall RF, Weller DM, Thomashow LS (1997) Quantification of 2,4-diacetylphloroglucinol produced by fluorescent Pseudomonas spp. in vitro and in the rhizosphere of wheat. Appl Environ Microbiol 63:951-955

> Brendel N, Partida-Martinez LP, Scherlach K, Hertweck C (2007) A cryptic PKS-NRPS gene locus in the plant commensal Pseudomonas fluorescens Pf-5 codes for the biosynthesis of an antimitotic rhizoxin complex. Org Biomol Chem 5:2211-2213

> Brodhagen M, Henkels MD, Loper JE (2004) Positive autoregulation and signaling properties of pyoluteorin, an antibiotic produced by the biological control organism Pseudomonas fluorescens Pf-5. Appl Environ Microbiol 70:1758-1766

Buckingham J (2011) Dictionary of natural products on DVD. Chapman \& Hall, London

> Cole JR, Chai B, Farris RJ, Wang Q and others (2007) The ribosomal database project (RDP-II): introducing myRDP space and quality controlled public data. Nucleic Acids Res 35:D169-D172

Cole JR, Wang Q, Cardenas E, Fish J and others (2009) The Ribosomal Database Project: improved alignments and new tools for rRNA analysis. Nucleic Acids Res 37: D141-D145

> de Souza JT, Arnould C, Deulvot C, Lemanceau P and others (2003) Effect of 2,4-diacetylphloroglucinol on Pythium: cellular responses and variation in sensitivity among propagules and species. Phytopathology 93:966-975

Dubuis C, Keel C, Haas D (2007) Dialogues of root-colonizing biocontrol pseudomonads. Eur J Plant Pathol 119: 311-328

Egan S, Thomas T, Kjelleberg S (2008) Unlocking the diversity and biotechnological potential of marine surface associated microbial communities. Curr Opin Microbiol $11: 219-225$ 
Engel S, Jensen PR, Fenical W (2002) Chemical ecology of marine microbial defense. J Chem Ecol 28:1971-1985

- Felsenstein J (1981) Evolutionary trees from DNA sequences: a maximum likelihood approach. J Mol Evol 17:368-376

Gachon CMM, Sime-Ngando T, Strittmatter M, Chambouvet A, Kim GH (2010) Algal diseases: spotlight on a black box. Trends Plant Sci 15:633-640

Goecke F, Labes A, Wiese J, Imhoff JF (2010) Chemical interactions between marine macroalgae and bacteria. Mar Ecol Prog Ser 409:267-299

> Guindon S, Lethiec F, Duroux P, Gascuel O (2005) PHYML Online-a web server for fast maximum likelihoodbased phylogenetic inference. Nucleic Acids Res 33: W557-W559

- Hayashida S, Tanaka S, Teramoto Y, Nanri N and others (1991) Isolation of anti-algal Pseudomonas stutzeri strains and their lethal activity for Chattonella antiqua. Agric Biol Chem 55:787-790

> Isnansetyo A, Kamei Y (2009) Bioactive substances produced by marine isolates of Pseudomonas. J Ind Microbiol Biotechnol 36:1239-1248

> Isnansetyo A, Horikawa M, Kamei Y (2001) In vitro antimethicillin-resistant Staphylococcus aureus activity of 2,4-diacetylphloroglucinol produced by Pseudomonas sp. AMSN isolated from a marine alga. J Antimicrob Chemother 47:724-725

> Isnansetyo A, Cui L, Hiramatsu K, Kamei Y (2003) Antibacterial activity of 2,4-diacetylphloroglucinol produced by Pseudomonas sp. AMSN isolated from a marine alga, against vancomycin-resistant Staphylococcus aureus. Int J Antimicrob Agents 22:545-547

> Iwasaki S, Kobayashi H, Furukawa J, Namikoshi M and others (1984) Studies on macrocyclic lactone antibiotics. VII. Structure of a phytotoxin 'rhizoxin' produced by Rhizopus chinensis. J Antibiot (Tokyo) 37:354-362

> Jensen PR, Fenical W (1994) Strategies for the discovery of secondary metabolites from marine bacteria: ecological perspectives. Annu Rev Microbiol 48:559-584

> Jousset A, Lara E, Wall LG, Valverde C (2006) Secondary metabolites help biocontrol strain Pseudomonas fluorescens $\mathrm{CHA0}$ to escape protozoan grazing. Appl Environ Microbiol 72:7083-7090

Kalinovskaya NI, Ivanova EP, Alexeeva YV, Gorshkova NM and others (2004) Low-molecular-weight, biologically active compounds from marine Pseudoalteromonas species. Curr Microbiol 48:441-446

Keel C, Weller DM, Natsch A, Defago G and others (1996) Conservation of the 2,4-diacetylphloroglucinol biosynthesis locus among fluorescent Pseudomonas strains from diverse geographic locations. Appl Environ Microbiol 62:552-563

Kielwein G (1971) Die Isolierung und Differenzierung von Pseudomonaden aus Lebensmitteln. Arch Lebensmittelhyg 22:29-37

- Kiyoto S, Kawai Y, Kawakita T, Kino E and others (1986) A new antitumor complex, WF-1360, WF-1360A, B, C, D, E and F. J Antibiot (Tokyo) 39:762-772

König GM, Kehraus S, Seibert SF, Abdel-Lateff A, Müller D (2006) Natural products from marine organisms and their associated microbes. ChemBioChem 7:229-238

Kremer BP, Markham JW (1979) Carbon assimilation by different developmental stages of Laminaria saccharina. Planta 144:497-501

Kumar S, Tamura K, Nei M (2004) MEGA3: integrated soft- ware for molecular evolutionary genetics analysis and sequence alignment. Brief Bioinform 5:150-163

Lane AL, Kubanek J (2008) Secondary metabolite defenses against pathogens and biofoulers. In: Amsler CD (ed) Algal chemical ecology. Springer, Berlin \& Heidelberg, p 229-243

Larkin MA, Blackshields G, Brown NP, Chenna R and others (2007) Clustal W and Clustal X version 2.0. Bioinformatics 23:2947-2948

> Loper JE, Henkels MD, Shaffer BT, Valeriote FA, Gross H (2008) Isolation and identification of rhizoxin analogs from Pseudomonas fluorescens Pf-5 by using a genomic mining strategy. Appl Environ Microbiol 74:3085-3093

> Nowak-Thompson B, Gould SJ, Kraus J, Loper JE (1994) Production of 2,4-diacetylphloroglucinol by the biocontrol agent Pseudomonas fluorescens Pf-5. Can JMicrobiol 40:1064-1066

> Obluchinskaya ED (2008) Comparative chemical composition of the Barents Sea brown algae. Appl Biochem Microbiol 44:305-309

Partida-Martinez LP, Hertweck C (2005) Pathogenic fungus harbours endosymbiotic bacteria for toxin production. Nature 437:884-888

Peix A, Ramírez-Bahena MH, Velázquez E (2009) Historical evolution and current status of the taxonomy of genus Pseudomonas. Infect Genet Evol 9:1132-1147

Penesyan A, Kjelleberg S, Egan S (2010) Development of novel drugs from marine surface associated microorganisms. Mar Drugs 8:438-459

Perrière G, Gouy M (1996) WWW-query: an on-line retrieval system for biological sequence banks. Biochimie 78: 364-369

Potin P (2002) Biotic interactions of marine algae. Curr Opin Plant Biol 5:308-317

> Ramette A, Frapolli M, Fischer-Le Saux M, Gruffaz C and others (2011) Pseudomonas protegens sp. nov., widespread plant-protecting bacteria producing the biocontrol compounds 2,4-diacetylphloroglucinol and pyoluteorin. Syst Appl Microbiol 34:180-188

Rao D, Webb JS, Holmström C, Case R and others (2007) Low densities of epiphytic bacteria from the marine alga Ulva australis inhibit settlement of fouling organisms. Appl Environ Microbiol 73:7844-7852

Rico A, Preston GM (2008) Pseudomonas syringae pv. tomato DC3000 uses constitutive and apoplast-induced nutrient assimilation pathways to catabolize nutrients that are abundant in the tomato apoplast. Mol Plant Microbe Interact 21:269-282

Saitou N, Nei M (1987) The neighbor-joining method: a new method for reconstructing phylogenetic trees. Mol Biol Evol 4:406-425

- Sawabe T, Ezura Y, Kimura T (1992) Characterization of an alginolytic marine bacterium from decaying Rishirikombu Laminaria japonica var. ochotensis. Bull Jpn Soc Sci Fish 58:141-145

Sawabe T, Makino H, Tatsumi M, Nakano K and others (1998) Pseudoalteromonas bacteriolytica sp. nov., a marine bacterium that is the causative agent of red spot disease of Laminaria japonica. Int J Syst Bacteriol 48: 769-774

- Sawabe T, Tanaka R, Iqbal MM, Tajima K and others (2000) Assignment of Alteromonas elyakovii KMM 162T and five strains isolated from spot-wounded fronds of Laminaria japonica to Pseudoalteromonas elyakovii comb. nov. and the extended description of the species. Int J 
Syst Evol Microbiol 50:265-271

Scherlach K, Partida-Martinez LP, Dahse HM, Hertweck C (2006) Antimitotic rhizoxin derivatives from a cultured bacterial endosymbiont of the rice pathogenic fungus Rhizopus microsporus. J Am Chem Soc 128:11529-11536

Schmidt EW (2005) From chemical structure to environmental biosynthetic pathways: navigating marine invertebratebacteria associations. Trends Biotechnol 23:437-440

Schneemann I, Kajahn I, Ohlendorf B, Zinecker H and others (2010a) Mayamycin, a cytotoxic polyketide from a Streptomyces strain isolated from the marine sponge Halichondria panicea. J Nat Prod 73:1309-1312

Schneemann I, Nagel K, Kajahn I, Labes A and others (2010b) Comprehensive investigation of marine Actinobacteria associated with the sponge Halichondria panicea. Appl Environ Microbiol 76:3702-3714

Stanier RY, Palleroni NJ, Doudoroff M (1966) The aerobic pseudomonads: a taxonomic study. J Gen Microbiol 43: 159-271

Staufenberger T, Thiel V, Wiese J, Imhoff JF (2008) Phylogenetic analysis of bacteria associated with Laminaria saccharina. FEMS Microbiol Ecol 64:65-77
Tatusova TA, Madden TL (1999) BLAST 2 Sequences, a new tool for comparing protein and nucleotide sequences. FEMS Microbiol Lett 174:247-250

Thiel V, Neulinger SC, Staufenberger T, Schmaljohann R, Imhoff JF (2007) Spatial distribution of sponge-associated bacteria in the Mediterranean sponge Tethya aurantium. FEMS Microbiol Ecol 59:47-63

Thomas T, Evans FF, Schleheck D, Mai-Prochnow A and others (2008) Analysis of the Pseudoalteromonas tunicata genome reveals properties of a surface-associated life style in the marine environment. PLoS ONE 3:e3252

- Weller DM (2007) Pseudomonas biocontrol agents of soilborne pathogens: looking back over 30 years. Phytopathology 97:250-256

> Weller DM, Landa BB, Mavrodi OV, Schroeder KL and others (2007) Role of 2,4-diacetylphloroglucinol-producing fluorescent Pseudomonas spp. in the defense of plant roots. Plant Biol 9:4-20

Wiese J, Thiel V, Nagel K, Staufenberger T, Imhoff JF (2009) Diversity of antibiotic-active bacteria associated with the brown alga Laminaria saccharina from the Baltic Sea. Mar Biotechnol (NY) 11:287-300

Appendix 1. Conditions applied for the growth inhibition assays. $\mathrm{OD}_{600}$ : optical density at $600 \mathrm{~nm}$

\begin{tabular}{|c|c|c|c|c|c|c|c|}
\hline $\begin{array}{l}\text { Test } \\
\text { strain }\end{array}$ & $\begin{array}{l}\text { Cell density } \\
\text { of inoculum }\end{array}$ & Medium & $\begin{array}{l}\text { Temp. } \\
\left({ }^{\circ} \mathrm{C}\right)\end{array}$ & $\begin{array}{c}\text { Aerobe/ } \\
\text { anaerobe }\end{array}$ & $\begin{array}{l}\text { Light/ } \\
\text { dark }\end{array}$ & $\begin{array}{c}\text { Time } \\
\text { (h) }\end{array}$ & $\begin{array}{l}\text { Shaking/ } \\
\text { standing }\end{array}$ \\
\hline \multicolumn{8}{|l|}{ Gram-positive bacteria } \\
\hline Bacillus subtilis & $\mathrm{OD}_{600}=0.02$ & TSB3+ & 28 & Aerobe & Dark & $14-16$ & $600 \mathrm{rpm}$ \\
\hline Staphylococcus lentus & $\mathrm{OD}_{600}=0.02$ & TSB3+ & 28 & Aerobe & Dark & $14-16$ & $600 \mathrm{rpm}$ \\
\hline \multicolumn{8}{|l|}{ Gram-negative bacteria } \\
\hline Escherichia coli & $\mathrm{OD}_{600}=0.03$ & TSB12+ & 28 & Aerobe & Dark & $14-16$ & $600 \mathrm{rpm}$ \\
\hline Pseudomonas fluorescens & $\mathrm{OD}_{600}=0.03$ & TSB12+ & 28 & Aerobe & Dark & $14-16$ & $600 \mathrm{rpm}$ \\
\hline \multicolumn{8}{|l|}{ Yeast } \\
\hline Candida glabrata & $\mathrm{OD}_{600}=0.05$ & M186 & 28 & Aerobe & Dark & $14-16$ & $600 \mathrm{rpm}$ \\
\hline \multicolumn{8}{|l|}{ Clinically relevant bacteria } \\
\hline Pseudomonas aeruginosa & $\mathrm{OD}_{600}=0.03$ & TSB12+ & 37 & Aerobe & Dark & $14-16$ & $600 \mathrm{rpm}$ \\
\hline Propionibacterium acnes & $\mathrm{OD}_{600}=0.03$ & PGY & 37 & Anaerobe & Dark & 48 & Standing \\
\hline \multicolumn{8}{|l|}{ Clinically relevant fungi } \\
\hline Trichophyton mentagrophytes & $5 \times 10^{4}$ spores $\mathrm{ml}^{-1}$ & SA & 28 & Aerobe & Dark & 72 & $120 \mathrm{rpm}$ \\
\hline Trichophyton rubrum & $5 \times 10^{4}$ spores $\mathrm{ml}^{-1}$ & SA & 28 & Aerobe & Dark & 72 & $120 \mathrm{rpm}$ \\
\hline \multicolumn{8}{|l|}{ Phytopathogenic bacteria } \\
\hline Pseudomonas syringae & $\mathrm{OD}_{600}=0.03$ & TSB12+ & 28 & Aerobe & Dark & $14-16$ & $600 \mathrm{rpm}$ \\
\hline Xanthomonas campestris & $\mathrm{OD}_{600}=0.03$ & TSB12+ & 28 & Aerobe & Dark & $14-16$ & $600 \mathrm{rpm}$ \\
\hline Erwinia amylovora & $\mathrm{OD}_{600}=0.03$ & TSB12+ & 28 & Aerobe & Dark & $14-16$ & $600 \mathrm{rpm}$ \\
\hline Ralstonia solanacearum & $\mathrm{OD}_{600}=0.03$ & M1 & 28 & Aerobe & Dark & $14-16$ & $600 \mathrm{rpm}$ \\
\hline \multicolumn{8}{|l|}{ Phytopathogenic fungi } \\
\hline Botrytis cinerea & $5 \times 10^{4}$ spores $\mathrm{ml}^{-1}$ & MA & 20 & Aerobe & Dark & 48 & Standing \\
\hline Phytophthora infestans & $1 \times 10^{4}$ spores ml ${ }^{-1}$ & PM & 20 & Aerobe & Dark & 72 & Standing \\
\hline Septoria tritici & $\mathrm{OD}_{600}=0.05$ & MYA & 20 & Aerobe & 16 h light:8 h dark & 48 & $600 \mathrm{rpm}$ \\
\hline \multicolumn{8}{|l|}{ Algae pathogenic bacteria } \\
\hline Pseudoalteromonas elyakovii & $\mathrm{OD}_{600}=0.01$ & MB & 28 & Aerobe & Dark & $14-16$ & $600 \mathrm{rpm}$ \\
\hline Algicola bacteriolytica & $\mathrm{OD}_{600}=0.03$ & $\mathrm{MB}$ & 28 & Aerobe & Dark & $14-16$ & $600 \mathrm{rpm}$ \\
\hline
\end{tabular}

